\title{
Indian Women Mathematicians
}

\author{
Mrs. M. Durga Devi ${ }^{1}$, Ms. K. Sumithra ${ }^{2}$
}

${ }^{1}$ M. Sc, MCA, M. Tech, Asst. Professor, Department of M.Sc. Mathematics, CH.S.D. St. Theresa's Autonomous College, Eluru, Andhra Pradesh.

${ }^{2}$ Pursuong II M.Sc Mathematics, CH.S.D. ST. Theresa's College For Women (A), ELURU.

\begin{tabular}{ll}
\hline ARTICLE INFO & ABSTRACT \\
\hline Published Online: & As time passed, numerous mathematicians gravitated towards universities. An emphasis \\
& on free thinking and trial had begun in Britain's oldest universities beginning in the \\
& seventeenth century at Oxford with the scientists Robert Hooke and Robert Boyle, and at \\
& Cambridge where Isaac Newton was Physics. Science and mathematics in the Islamic \\
& world during the Middle Periods followed colourful models and modes of backing varied \\
& grounded primarily on scholars. It was expansive patronage and strong intellectual \\
& programs enforced by specific autocrats that allowed scientific knowledge to develop in \\
& numerous areas. A mathematician is someone who uses an expansive knowledge of \\
& mathematics in their work, generally to break fine problems. Mathematicians are \\
Corresponding Author: & concerned with figures, data, volume, structure, space, models, and change. \\
\hline
\end{tabular}

KEYWORDS: Mathematics, Mathematicians, Science, Knowledge.

\section{INTRODUCTION}

The word mathematics comes from the ancient Greeks and is deduced from the word máthēma, meaning that which is learnt," according to Douglas R. Harper, author of the"Online Etymology Dictionary."The ancient Greeks erected on other ancient societies' fine studies, and they developed the model of abstract mathematics through figure.

Mathematics is the wisdom that deals with the sense of shape, volume and arrangement. Math is each around us, in everything we do. It's the structure block for everything in our diurnal lives, including mobile bias, computers, software, armature (ancient andultramodern), art, plutocrat, engineering and indeed sports. As societies developed, mathematicians began to work with figure, which computes areas, volumes and angles, and has numerous practical operations. Figure is used in everything from home construction to fashion and interior design. As RichardJ. Gilling's wrote in his book "Mathematics in the Time of the Dictators" (Dover Publications, 1982), the conglomerations of Giza in Egypt are stunning exemplifications of ancient societies' advanced use of figure.

Algebra offered societies a way to divide birthrights and allocate resources. The study of algebra meant mathematicians could break direct equations and systems, as well as quadratics, and claw into positive and negative results. Mathematicians in ancient times also began to look at number proposition, which"deals with parcels of the whole numbers, 1, 2, 3, 4, 5...,"TomM. Apostol, a professor at the California Institute of Technology, wrote in"Preface to Analytic Number Theory" (Springer, 1976). With origins in the construction of shape, number proposition looks at figurate numbers, the characterization of numbers, and theorems.

\section{WHY MATHEMATICS IS IMPORTANT}

It's not uncommon for people to wonder what connection mathematics serves in their quotidian lives. In the modern world, computation analogous as applied mathematics is not only applicable, it's vital. Applied mathematics covers the branches that study the physical, natural or sociological world. "The thing of applied mathematics is to establish the connections between separate academic fields," wrote Alain Goriely in"Applied Mathematics a Truly Short Prolusion" (Oxford University Press, 2018). Modern areas of applied computation include fine medicines, fine biology, control proposition, aerospace engineering and computation finance. Not only does applied computation break problems, but it also discovers 
new problems or develops new engineering disciplines, Goriely added. The common approach in applied computation is to make a fine model of a phenomenon, break the model and develop recommendations for performance improvement.

While not inescapably a contrary to applied mathematics, pure mathematics is driven by abstract problems, rather than real- world problems. Important of the subjects that are pursued by pure mathematicians have their roots in concrete physical problems, but a deeper understanding of these marvels brings about problems and oddities. These abstract problems and oddities are what pure mathematics attempts to break, and these attempts have led to major discoveries for humankind, including the universal Turing machine, theorized by Alan Turing in 1937. This machine, which began as an abstract idea, latterly laid the root for the development of ultramodern computers. Pure mathematics is abstract and grounded in proposition, and is therefore not constrained by the limitations of the physical world. According to Goriely, "Applied mathematics is to pure mathematics, what pop music is to classical music." Pure and applied aren't mutually exclusive, but they're embedded in different areas of calculation and problem working. Though the complex calculation involved in pure and applied mathematics is beyond the understanding of utmost people, the results developed from the processes have affected and bettered the lives of numerous.

\section{WOMEN MATHEMATICIANS IN INDIA}

India is the land of some of the topmost minds. From Literature and Wisdom sluice to Art and Theatre, India has been a colonist in all the fields because of the exceptionally talented individualities who made the country proud. Mathematics, as a discipline, continues to be of utmost significance in the world and this blog explores some of the notorious Indian mathematicians and their donation to the world of mathematics. These mathematicians challenged the understanding of the world and left behind a heritage of advance discovery and exploration. Let us explore these notorious Indian Mathematicians who are still deified worldwide for their significant benefactions!
1. Raman Parimala
2. Neena Gupta
3. Shakuntala Devi
4. Sujhata Ramdorai
5. Mangala Narlikar
6. Vanaja Iyengar
7. Renuka Ravindra
8. Ajit Iqbal Singh
9. T. A. Sarasvati Amma
10. Bhama Srinivasan

Raman Parimala (born 21 November 1948) is an Indian mathematician known for her benefactions to algebra. She's the Trades \&Lore's Distinguished Professor of mathematics at Emory University. For numerous times, she was a professor at Tata Institute of Fundamental Research (TIFR), Mumbai. Raman has made outstanding benefactions to algebra using tools of number proposition, algebraic figure, and topology. Among her notable benefactions are publishing the first illustration of a nontrivial quadratic space over an affine aeroplane. She has also worked on a result for the alternate Serre guess. Parimala works in algebra. Her exploration uses tools from number proposition, algebraic figure, and topology. She's a fellow of all three Indian seminaries of wisdom. She was an invited speaker at the International Congress of Mathematicians in Zürich in 1994 and a grand speaker at the 2010 ICM in Hyderabad. Her exploration has been honoured with the Bhatnagar Prize in 1987, a memorial doctorate from the University of Lausanne in 1999, and the Srinivasa Ramanujan Birth Centenary Award in 2003. Parimala entered the 2005 prize in mathematics from the Academy of Lore's for the Developing World for "her work on the quadratic analogue of Serre's guess, the negligibility of top homogeneous spaces of classical groups over fields of cohomological confines 2 and the $\mu$ steady of p-adic function fields." Prizes in the quantum of $\$$ are awarded annually to scientists from developing countries who have made outstanding benefactions to the advancement of wisdom. This was the first time in the 20time history of the TWAS awards that a woman had been recognized with the prize in either mathematics or drugs. Neena Gupta (born in 1984) is a professor at the Statistics and Mathematics Unit of the Indian Statistical Institute (ISI), Kolkata. Her primary fields of interest are commutative algebra and affine algebraic figure. Neena Gupta was preliminarily a visiting scientist at the ISI and a visiting fellow at the Tata Institute of Fundamental Research (TIFR). She has won (2) Shanti Swarup Bhatnagar award (2019) in the order of fine lore's, the loftiest honour in India in the field of wisdom and technology.

Neena Gupta entered the Indian National Science Academy Young Scientist award in 2014 for the result she proposed to the Zariski Cancellation Problem. in positive characteristic. Her work on the guess had also earned her the initial Saraswathi Cowsik Medal in 2013, awarded by the TIFR Alumni Association. She's also the philanthropist of Abdus Salam ICTP's Ramanujan Prize for Young Mathematicians from Developing Countries in 2021.

Shakuntala Devi (4 November 1929 - 21 April 2013) was an Indian mathematician, pen and internal calculator, popularly known as the "Human Computer". Her gift earned her a place in the 1982 edition of The Guinness Book of World Records. Still, the instrument for the 
record was given posthumously on 30 July 2020, despite Devi achieving her world record on 18 June 1980 at Imperial College, London. Devi was an unseasonable child and she demonstrated her computation capacities at the University of Mysore without any formal education. Devi travelled to several countries around the world demonstrating her computation bents. She was on a stint of Europe throughout 1950 and was in New York City in 1976. In 1988, she travelled to the US to have her capacities studied by Arthur Jensen, a professor of educational psychology at the University of California, Berkeley. Jensen tested her performance at several tasks, including the computation of large figures. Exemplifications of the problems presented to Devi included calculating the cell root of and the seventh root of. Jensen reported that Devi handed the result to the over mentioned problems (395 and 15, independently) before Jensen could copy them down in his tablet.Jensen published his findings in the academic journal Intelligence in 1990.

Sujatha Ramdorai (born 1962) is an algebraic number philosopher known for her work on Iwasawa proposition. She's a professor of mathematics and Canada Research Chair at University of British Columbia, Canada. She was preliminarily a professor at Tata Institute of Fundamental Research.

A good training in mathematics helps you develop your logical faculties \& to suppose logically. Pure mathematics by itself, finds unanticipated operations in areas ranging from medical imaging to internet security, transportation,etc. to name just a many. Dr.Ramdorai originally worked in the areas of algebraic proposition of quadratic forms and computation figure of elliptic angles. Together with Coates, Fu kaya, Kato, and Ven Jakob she formulated anon-commutative interpretation of the main guess of Iwasawa proposition, on which important foundation of this important subject is grounded. Working with her hubby Srinivasan Ramdorai and Indian mathematics penV.S. Sastry, Sujatha Ramdorai conceived of and incompletely funded the Ramanujan Math Park in Chittoor, Andhra Pradesh, which was inaugurated at the end of 2017. The demesne is devoted to mathematics education and honours the great Indian mathematician Srinivasa Ramanujan (1887-1920). Ramdorai came the first Indian to win the prestigious ICTP Ramanujan Prize in 2006. She was also awarded the Shanti Swarup Bhatnagar Award, the loftiest honour in scientific fields by the Indian Government in 2004.

Mangala Narlikar is an Indian mathematician who has done disquisition in pure mathematics as well as written for a lay cult. After her degrees in mathematics, she firstly worked at the Tata Institute of Fundamental Research (TIFR) in Mumbai and subsequently worked as a speaker in the University of Bombay and Pune. Narlikar's core fields of interest are real and complex analysis, logical figure, number proposition, algebra, and topology. On writing books on mathematics, Narlikar wrote"I enjoyed writing a book on how to make mathematics interesting and accessible". On her combining her profession with looking after the ménage functions she wrote"My story is perhaps a representation of the lives of multitudinous women of my generation who are well educated but always put ménage arrears before their particular careers".

Vanaja Iyengar (failed 2001) was an Indian mathematician, educator and the author vice-chancellor of Sri Padmavati Mahila Visvavidyalayam, Tirupati, in the south Indian state of Andhra Pradesh. She was one of the authors of the Andhra Mahila Sabha School of Informatics. The Government of India awarded her the fourth loftiest mercenary honour of Padma Shri in 1987. Born in the concentrated Andhra Pradesh, she completed her early education at Hyderabad and attained advanced education in Mathematics from Cambridge University in 1950, after which she visited Yugoslavia, Czechoslovakia and Hungary as a part of pupil forums. Her career started as a member of faculty at Osmania University and worked in two of the sodalities combined to the university, University College for Women, Koti (Osmania Women's College) and Nizam College. In 1987, the Government of India awarded Iyengar the mercenary honour of Padma Shri. She entered the Stylish Schoolteacher award from the Government of Andhra Pradesh and was a fellow of the Rajiv Gandhi Foundation. She failed in 2001, survived by her hubby, Mohit Sen, a known socialist geek, who also failed two times latterly.

Ajit Iqbal Singh (born 1943) is an Indian mathematician, specializing in functional analysis and harmonious analysis. Singh is a Fellow of the Indian National Science Academy (INSA), India's apex body of scientists and technologists. She's also a fellow of the National Academy of Lore's (India), predicated in Allahabad. Singh has worked on direct motorists in locally convex spaces, topological algebra, spectral emulsion in hyperactive groups, multipliers and module homeomorphisms, semi group algebras, operations of harmonious analysis to discriminative equations and orthogonal polynomials, figure of the range of a vector measure, and quotient rings of algebras of functions and motorists.

T.A. Sarasvati Amma (Tekkath Amayankottukurussi Kalathil Sarasvati, also spelled as T.A. Saraswathi Amma) (26 December 1918 - 15 August 2000) was a scholar born in Cherpulassery, Palakkad District, Kerala, India. She has contributed to the fields of history of Mathematics and Sanskrit, through her work on Figure of ancient and medieval

India.

The Kerala Mathematical Association started aregularProf.T.A. Sarasvati Amma Memorial Lecture in its periodic conference in 2002. In the words of Michio 
Yano, who reviewed Sarasvati Amma's book Figure in Ancient and Medieval India, the book" established a firm foundation for the study of Indian figure". Her book Figure in Ancient and Medieval India is a check of the Sanskrit and Prakrit scientific andquasi-scientific literature of India, beginning with the Vedic literature and ending with the early part of the 17 th century. It deals in detail with the Sulba Sutras in the Vedic literature, with the fine corridor of Jaina Canonical works and of the Hindu Siddhantas and with the contributions to figure made by the astronomer mathematicians Aryabhata I \& II, Sripati, Bhaskara I \& II, Sangamagrama Madhava, Paramesvara, Nilakantha, his epigones and a host of others. The factory of the mathematicians Mahavira, Sridhara and Narayana Pandita and the Bakshali Manuscript have also been studied. The work seeks to explode the proposition that the Indian fine genius was generally algebraic and computational and that it escaped evidences and accounts. There was an academy in India which delighted in geometric demonstrations of algebraic results.

\section{CONCLUSION}

I wish to conclude initially by simply saying that the work of Indian women mathematicians has been severely done for next generations. The great Women Mathematicians did very well in their circumstances and gave fruitful to the next generations. we are very much thankful towards our great scientists.

\section{REFERENCES}

1. The Able committee 2011/2011 the Able prize.

2. "Kolkata mathematician wins Retrieved 7 October 2019.Bhatnagar award, youngest recipient till date Kolkata News - Times of India".

3. Shakuntala Devi strove to simplify maths for students. The Hindu. 21 April 2013. Retrieved 9 July 2013.

4. E-learning in Mathematics at Undergraduate and Postgraduate Level . Bhaskaracharya Pratishthana. Archived from the original on 20 April 2014. Retrieved 1 November 2015.

5. Chengalvarayan \& Gokilvani 2007, p. 110. 